\title{
The Relative Financial Cost and Benefit of an Ophthalmology Resident Compared to an Advanced Practice Provider, Optometrist, or Faculty Ophthalmologist
}

\author{
Daniel B. Moore, MD ${ }^{1}$ William Barr, MBA ${ }^{2}$ \\ ${ }^{1}$ Department of Ophthalmology, University of Kentucky, Lexington, \\ Kentucky \\ ${ }^{2}$ Department of Finance, University of Kentucky, Lexington, Kentucky \\ Address for correspondence Daniel B. Moore, MD, Department of \\ Ophthalmology and Visual Sciences, University of Kentucky, 110 Conn \\ Terrace, Suite 550, Lexington, KY 40508 \\ J Acad Ophthalmol 2018;10:e185-e188. \\ (e-mail: daniel.b.moore@uky.edu).
}

\begin{abstract}
Keywords

- resident education

- cost of training

- housestaff

- cost of education

Objective The main objective of the article is to determine the relative direct financial cost and benefit of an advanced practice provider (APP), optometrist, and faculty ophthalmologist compared with an ophthalmology resident.

Design Single center cost-benefit financial analysis.

Methods The direct total expenses, including mean salary and benefits; the cost/ week, based upon calculated hours worked; and net revenue, based upon technical collections subtracted from total expenses were collected for all APPs, optometrists, faculty ophthalmologists, and ophthalmology residents at the University of Kentucky for the 2016 to 2017 academic year. Optometry and ophthalmology faculty collections were adjusted for clinical full-time equivalents.

Results Total annual mean salary and benefits for 242 APPs, 4 optometrists, 17 faculty ophthalmologists, and 9 ophthalmology residents were $\$ 126,797, \$ 117,021, \$ 338,233$, and $\$ 71,210$, respectively. Assuming a 50 -hour-work week, the calculated hourly costs were $\$ 48.77, \$ 45.01, \$ 130.09$, and $\$ 27.39$, respectively. Ophthalmology residents do not directly generate work relative value units or collections. On this basis, the net annual revenues were $-\$ 62,729, \$ 122,757, \$ 566,119$, and $-\$ 71,210$, respectively.

Conclusions Ophthalmology residents are relatively inexpensive compared with potential substitute health care providers, although they are unable to generate direct revenue. Indirect costs and benefits are likely substantial, but currently incalculable. More candid analyses of the role and financial impact of trainees in health care are needed.
\end{abstract}

Medical training has historically been an apprenticeship, variably balancing service and education. Despite increasing regulation and oversight, the argument of whether a resident physician is a student or employee remains unresolved. On one hand, the National Labor Relations Board in 1999 ruled residents are employees under the National Labor Relations Act. ${ }^{1}$ On the other hand, Graduate Medical Education (GME) has been subsidized since the signing of Titles XVII and XIX of the Social Security Act in 1965 and the establishment of

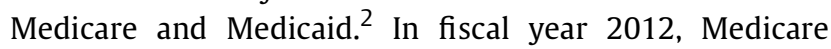
provided approximately $\$ 9.7$ billion in funding to hospitals for GME, with more than two-thirds ( $\$ 6.8$ billion) designated as indirect payments. Intended to help defray the assumed and uncalculated increased costs of providing patient care in received

July 7, 2018

accepted after revision

November 20, 2018
DOI https://doi.org/

10.1055/s-0038-1676856. ISSN 2475-4757.
Copyright $\odot 2018$ by Thieme Medical Publishers, Inc., 333 Seventh Avenue, New York, NY 10001, USA. Tel: +1(212) 584-4662.
License terms

(이 (1) $\Theta \circledast$ 
a teaching hospital, these indirect payments have repeatedly been the target of budget cuts by regulatory bodies. ${ }^{3,4}$ In fact, a 2014 report from the Institute of Medicine recommended replacing the current payment model for GME, noting "remarkably little is known about the individual, institutional, and societal costs of residency training ... Federal GME regulations are nearly silent regarding transparency and accountability for use of Medicare GME funds." 5

Federal funding cuts for teaching hospitals have understandably been met with concern; a national survey of GME directors suggested that even a modest decrease in indirect Medicare reimbursement would likely trigger downsizing of impacted programs. ${ }^{6}$ Since the training of residents presumably leads to increased hospital costs, replacing or augmenting housestaff with advanced practice providers (APPs) is one potential response to projected budgetary constraints. ${ }^{7,8} \mathrm{We}$ performed a direct cost-benefit analysis of this theoretical approach in the Department of Ophthalmology at the University of Kentucky, evaluating a small component of the cost structure for the particular types of personnel involved in delivering care.

\section{Materials and Methods}

To determine cost, the total mean salary and benefits of all APPs (nurse practitioners, clinical nurse specialists, nurse anesthetists, and physician assistants), optometrists, faculty ophthalmologists, and ophthalmology residents at the University of Kentucky were determined utilizing available financial data for fiscal year 2017. The resident salary and benefits represented the mean for the complement of ophthalmology residents. APPs, optometrists, and faculty are salaried and the salary and benefits represent the mean for all APPs in the College of Medicine and all optometrists and faculty ophthalmologists in the Department of Ophthalmology. The cost per week based on mean number of hours worked was calculated for each group, as determined by the mean number of hours worked. The number of hours worked/week for residents was the mean of 2016 to 2017 duty hour logs per Accreditation Council for Graduate Medical Education (ACGME) requirements; for APPs, it was based upon institutional fiscal calculations.

To determine benefit, the mean number of work relative value units (wRVUs), technical collections, and expenses for the three groups during fiscal year 2017 were tabulated. For optometrists and faculty ophthalmologists, these figures were adjusted for clinical full-time equivalents. Net revenue was technical collections subtracted from total expenses.

\section{Results}

Total annual mean salary and benefits for 242 APPs, 4 optometrists, 20 faculty ophthalmologists, and 9 ophthalmology residents were $\$ 126,797, \$ 117,021, \$ 338,233$, and $\$ 71,210$, respectively (-Table 1). APPs worked a maximum of 50 hours/week and ophthalmology residents worked an average of 60 hours/week. Given the variability in work hours across the four groups, an average of 50 hours/ week was selected to provide comparable analysis. On that basis, the calculated hourly cost was $\$ 48.77, \$ 45.01, \$ 130.09$, and \$27.39, respectively (- Table $\mathbf{1}$ ).

Total annual mean wRVUs and technical collections are presented in - Table 2. Ophthalmology residents do not directly generate wRVUs or collections. Accordingly, the net annual revenue was-\$62,729, $\$ 122,757, \$ 566,119$, and $-\$ 71,210$, respectively.

\section{Discussion}

A report by the RAND corporation in 2013 evaluating the financial impact of residency training programs concluded, "[i]f the hospital has service needs that would otherwise need to be met by hiring alternative providers, there is a marginal benefit to adding a resident, particularly in a subspecialty program, before considering the additional benefits of any GME-related revenues."7 A more recent analysis at the University of Massachusetts Medical School examining the opposite-the financial implications of reducing residency programs-found that decreasing the size of large programs results in higher replacement costs than the direct costs of residents, and the marginal gains from eliminating small programs are far smaller than the estimated shortfall if Medicare GME funding is reduced. ${ }^{8}$ Our study augments these results by demonstrating the significantly lower cost of a resident compared with a replacement APP, optometrist, or faculty ophthalmologist. At our institution, the hourly cost of an ophthalmology resident is 40,44 , and $23 \%$ of that of an APP, optometrist, or faculty

Table 1 Mean total salary, benefits and cost/hour of advanced practice providers, optometrists, faculty ophthalmologists, and ophthalmology residents

\begin{tabular}{|c|c|c|c|c|c|c|}
\hline \multicolumn{4}{|l|}{ Salary and benefits } & \multicolumn{3}{|c|}{ Cost/hour } \\
\hline Position & Salary & $\begin{array}{l}\text { Total } \\
\text { benefits }\end{array}$ & $\begin{array}{l}\text { Total } \\
\text { (salary + benefits) }\end{array}$ & $40 \mathrm{~h} / \mathrm{wk}$ & $50 \mathrm{~h} / \mathrm{wk}$ & $60 \mathrm{~h} / \mathrm{wk}$ \\
\hline APP & $\$ 98,456$ & $\$ 28,341.16$ & $\$ 126,797$ & $\$ 60.96$ & $\$ 48.77$ & $\$ 40.64$ \\
\hline Optometrist & $\$ 89,500$ & $\$ 27,520.77$ & $\$ 117,021$ & $\$ 56.26$ & $\$ 45.01$ & $\$ 37.51$ \\
\hline Ophthalmology faculty & $\$ 268,440$ & $\$ 69,794.15$ & $\$ 338,233$ & $\$ 162.61$ & $\$ 130.09$ & $\$ 108.41$ \\
\hline Ophthalmology resident & $\$ 54,570$ & $\$ 16,639.97$ & $\$ 71,210$ & $\$ 34.24$ & $\$ 27.39$ & $\$ 22.82$ \\
\hline
\end{tabular}

Abbreviation: APP, advanced practice provider.

Mean number of hours worked for each position. 
Table 2 Mean relative collections, expenses, and net revenue for advanced practice providers, optometrists, faculty ophthalmologists, and ophthalmology residents

\begin{tabular}{|l|l|l|l|l|}
\hline & APP & Optometrist $^{\mathrm{a}}$ & Ophthalmology faculty $^{\mathrm{a}}$ & Ophthalmology resident $^{-}$ \\
\hline wRVU & 1,477 & 5,234 & 10,991 & 0 \\
\hline Charges & $\$ 222,622$ & $\$ 701,467$ & $\$ 2,667,194$ & $\$ 0$ \\
\hline Payments & $\$ 64,048$ & $\$ 239,778$ & $\$ 904,352$ & $\$ 0$ \\
\hline Technical collections & $\$ 64,048$ & $\$ 239,778$ & $\$ 904,352$ & $\$ 0$ \\
\hline Total expenses & $\$ 126,777.00$ & $\$ 117,021$ & $\$ 338,233$ & $\$ 71,210$ \\
\hline Net income & $(\$ 62,729)$ & $\$ 122,757$ & $\$ 566,119$ & $(\$ 71,210)$ \\
\hline
\end{tabular}

Abbreviations: APP, advanced practice provider; wRVU, work relative value unit.

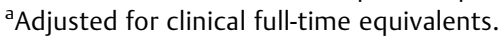

ophthalmologist. However, because resident physicians cannot bill for services, the direct revenue was notably disparate, with residents and APPs both generating net negative income compared with optometrists and faculty ophthalmologists. For the APPs, the negative income is mitigated by the increased clinical, hospital, and surgical productivity of physicians, and these projections are incorporated into overall cost analyses of each of these positions. Similar data are not currently available for resident physicians.

The number of APPs is growing at a rate greater than physicians, largely in response to the increasing divide between supply and demand in health care. In the field of ophthalmology, however, this has yet to occur; in 2015, there were reportedly only 70 physician assistants (PA) employed by ophthalmologists in the United States. ${ }^{9}$ Potential solutions proposed to address the demand include enhancing the scope of optometry, expanding the number of residency positions, increasing the workload of ophthalmologists, and/or utilizing APPs. ${ }^{10} \mathrm{~A}$ direct comparison of these employee groups is difficult, given an inclusive substitute for the clinical and surgical responsibilities of our trainees is not currently available. One very recent report attempting to bridge the gap from the Wilmer Eye Institute discussed outcomes after incorporating a PA into their consult service. The PA was a former comprehensive ophthalmologist in another country and works for 3.5 days a week, served as the primary responder for all consults, calling the secondyear resident on rotation only for those patients requiring surgical intervention, were of educational interest, had abnormal findings or required subspecialty consultation. The authors found most residents strongly agreed that having a PA both improved education and the balance between service and education. The PA has been cost neutral to the department, and the authors estimate the break-even point in their department is roughly 8 to 12 patient visits per day. ${ }^{11}$

Since resident physicians cannot independently bill for clinic visits or operative cases, they do not directly generate revenue, as demonstrated by the wide gap between costs and benefits in this analysis. Limited data and transparency surrounding trainee impact on hospital productivity are part of the reason GME funding is continually subject to scrutinization. ${ }^{12}$ As this analysis demonstrates from a direct cost comparison perspective, resident physicians are signifi- cantly cheaper sources of labor compared with any potential replacements. While it is not possible to calculate the indirect revenue generated by resident physicians, two studies of general surgery residents at single institutions estimated the unbilled revenue of a resident was $\$ 95,000^{13}$ or $\$ 233,000^{14}$ per year. A more recent multicenter prospective analysis determined unbilled consult services provided by orthopedic residents during on-call hours would fund $73 \%$ of the resident's stipends. ${ }^{15}$ Conversely, and as stated above, a calculation of indirect costs of resident physicians is currently problematic. While it is assumed that training a physician increases the time and costs of health care, there are limited data to support this. ${ }^{16}$ As institutions grapple with the overall financial impact of current and additional APPs, similar data should be collected and analyzed for our trainees.

Overlying any discussion on the role of resident physicians in the health care labor force is the perceived dichotomy between education and service, a fundamental oversight function of the ACGME. While the definition of service is necessarily imprecise, and service obligations can serve an educational role, ${ }^{17}$ any sincere effort to evaluate the utility of resident physicians in this context will need to consider educational objectives and well-being.

There are several important limitations to this analysis. It represents a single department at one academic medical center and it assumes that APP, optometry and ophthalmology faculty wRVU, and technical collections would remain unchanged if their job responsibilities mirrored the work of a resident physician. Further, residency programs and training environments are diverse, with university, veteran affairs, and community-based clinics as well as county or indigent locations. Programs that offer charity services in residentrun clinics are an important example of potential costs and benefits outside the scope of this analysis. Like most ophthalmology practices, ${ }^{10}$ we currently have no APPs employed in our department, so the comparison does not directly relate to ophthalmology-extenders. As stated above, we cannot accurately calculate any indirect costs or benefits. Lastly, this analysis focuses solely on the comparative financial cost and benefits of these providers. It does not address access to or quality of care or any societal need to train future care providers. As Albert Einstein is attributed with saying, "Not 
everything that can be counted counts, and not everything that counts can be counted."

In summary, we found resident physicians to be relatively inexpensive providers compared with APPs, ophthalmology faculty, or optometrists at our medical center. Because trainees are unable to bill for services, the net revenue was lower than the other groups. A comprehensive response to both predicted and unforeseen changes in health care will likely utilize a combination of options, but our data suggest that in academic centers, resident physicians are a relatively inexpensive source of labor compared with optometrists, faculty ophthalmologists, and APPs. As stakeholders continue to evaluate the landscape of health care and the role of different provider models in addressing evolving demands, we need to incorporate a frank and transparent discussion surrounding the role and financial implications of trainee involvement in care.

\section{Conflict of Interest}

None.

\section{References}

1 Schuster BL. Funding of Graduate Medical Education in a marketbased healthcare system. Am J Med Sci 2017;353(02):119-125

2 Rich EC, Liebow M, Srinivasan M, et al. Medicare financing of graduate medical education. J Gen Intern Med 2002;17(04): 283-292

3 Medicare Payment Advisory Commission. Report to the Congress: aligning incentives in Medicare. June 2010. Available at: http:// www.medpac.gov/docs/default-source/congressional-testimony/ 20100623_EandC_Testimony_AligningIncentivesinMedicare.pdf? sfvrsn $=0$. Accessed October 26, 2017

4 The National Commission on Fiscal Responsibility and Reform. The moment of truth. December 2010. Available at: http://www. momentoftruthproject.org/sites/default/files/TheMomentofTruth12_1_2010.pdf. Accessed October 26, 2017
5 Institute of Medicine. Graduate Medical Education that Meets the Nation's Health Needs. Washington, DC: National Academies Press; 2014

6 Riaz M, Palermo T, Yen M, Edelman NH. The projected response of residency-sponsoring institutions to a reduction in Medicare support for graduate medical education: a national survey. Acad Med 2015;90(10):1380-1385

7 Wynn BO, Smalley R, Cordasco KM. Does it cost more to train residents or to replace them?: A look at the costs and benefits of operating graduate medical education programs Rand Health $Q$ 2013;3(03):7 eCollection.

8 DeMarco DM, Forster R, Gakis T, Finberg RW. Eliminating residents increases the cost of care. J Grad Med Educ 2017;9(04): 514-517

9 Stephenson M. Is there a place for PAs in ophthalmology? Rev Ophthalmol 2015;13:52-58

10 Browning DJ. Physician assistants and nurse practitioners in ophthalmology - has the time come? Am J Ophthalmol 2018; 186:ix-xi

11 Lee B, D'Souza M, Singman EL, et al. Integration of a physician assistant into an ophthalmology consult service in an academic setting. Am J Ophthalmol 2018;190:125-133; Epub ahead of print

12 Sklar DP. Graduate Medical Education and the institute of medicine report. Acad Med 2014;89(12):1575-1577

13 Stoller J, Pratt S, Stanek S, Zelenock G, Nazzal M. Financial contribution of residents when billing as "junior associates" in the "surgical firm". J Surg Educ 2016;73(01):85-94

14 Feinstein AJ, Deckelbaum DL, Madan AK, McKenney MG. Unsupervised procedures by surgical trainees: a windfall for private insurance at the expense of graduate medical education. J Trauma 2011;70(01):136-139, discussion 139-140

15 Jackson JB III, Vincent S, Davies J, et al. A prospective multicenter evaluation of the value of the on-call orthopedic resident. J Grad Med Educ 2018;10(01):91-94

16 Committee on the Governance and Financing of Graduate Medical Education; Board on Health Care Services. Institute of Medicine; Eden J, Berwick D, Wilensky G, editors. Graduate medical education that meets the nation's health needs. Washington (DC): National Academies Press; 2014

17 Stoff BK, MacKelfresh JB, Stoddard HA. Education versus service in residency: a false dichotomy? J Grad Med Educ 2017;9(03):395-396 